\title{
An Inventory Model with Price and Quality Dependent Demand Where Some Items Produced Are Defective
}

\author{
Tapan Kumar Datta \\ BITS Pilani-Dubai Campus, Dubai International Academic City, P.O. Box 345055, Dubai, UAE \\ Correspondence should be addressed to Tapan Kumar Datta; dattap12@rediffmail.com
}

Received 24 January 2013; Revised 15 May 2013; Accepted 17 May 2013

Academic Editor: Ching-Jong Liao

Copyright (C) 2013 Tapan Kumar Datta. This is an open access article distributed under the Creative Commons Attribution License, which permits unrestricted use, distribution, and reproduction in any medium, provided the original work is properly cited.

This paper analyzes an inventory system for joint determination of product quality and selling price where a fraction of items produced are defective. It is assumed that only a fraction of defective items can be repaired/reworked. The demand rate depends upon both the quality and the selling price of the product. The production rate, unit price, and carrying cost depend upon the quality of the items produced. Quality index is used to determine the quality of the product. An algorithm is provided to solve the model with given values of model parameters. Sensitivity analysis has also been performed.

\section{Introduction}

In every business, product quality is an important factor that attracts customers. For durable goods, quality depends upon several factors. Some of such factors are type/quality of the raw materials used, type/quality of the machines used in the production process, skills of workers engaged in the production system, and so forth. It is obvious that the unit cost for a high quality product will be high. In general, unit cost increases with quality. Quality measure is an important issue in all production systems. There is no well-defined method for measuring quality. In fact, quality characteristics are not the same for all types of items. It varies from one type of items to another type. There are several research articles on quality measure. Maynes [1] described the concept of evaluating quality index as a measure of quality for durable goods. He suggested to combine characteristics of variety and the characteristics of seller to evaluate quality index. Jiang [2] defined quality index as a ratio of two different life measures based on fractile life; one represents life utilization extent and the other represents the quality improvement potential. He derived quality index formulae for several known lifetime distributions. Some authors proposed quality index method to measure quality of sea foods. Huidobro et al. [3] proposed quality determination method for raw Gilthead seabream (Sparusaurata) based on the quality parametersflesh elasticity, odor, clarity, shape of fish. Barbosa and VazPires [4] proposed the development of a sensorial scheme to measure quality of common octopus.

Though customers have the tendency to buy a high quality product, sometimes due to high price they compromise with the quality. Thus, a challenging task for a production manager is to produce units in suitable quality and setting a reasonable selling price for these units. Normally, customers' demand decreases when selling price increases.

In some production systems, all items manufactured are not good/perfect. This may be seen in failure-prone manufacturing system where the produced items are a mixture of good as well as defective items. This situation can be found in the industries where units are produced in large numbers. Some of the research articles on defective products are authored by Rosenblatt and Lee [5], Kim and Hong [6], Salameh and Jaber [7], Chung and Hou [8], Chiu [9], Sana [10], Datta [11], and Mhada et al. [12]. Rosenblatt and Lee [5] studied the effect of the imperfect production process on optimal production cycle. They assumed the system deteriorates during the production process and produces some proportion of defective items. Kim and Hong [6] analyzed a production system which deteriorates randomly and shifts from in-control state to outof-control state. They determined the optimal production 
run length. Salameh and Jaber [7] developed an EOQ model where all items produced are not perfect. They assumed that the imperfect items would be sold in a single batch by the end of the screening process. Chung and Hou [8] analyzed a system with deteriorating production process and allowable shortages. Chiu [9] developed a finite production rate model by assuming that a fraction of defective products can be reworked and the rest will be disposed. Sana [10] analyzed an inventory model to determine optimal product reliability, optimal production rate in a faulty production system. In his article, the demand rate is assumed to be time dependent. Datta [11] developed an inventory model with adjustable production rate and selling price sensitive demand rate. In his article, he assumed that all items produced are not perfect. This model jointly determines optimal production rate, production period, and selling price. Mhada et al. [12] proposed a model with perfectly mixed good and defective parts. But these research articles did not consider product quality as a decision parameter. Some researchers realized the importance of product quality and incorporated the quality factor in their models. Some of such articles are authored by Chen [13], Mahapatra and Maiti [14], Chen and Liu [15], and Chen [16]. Chen [13] developed a model to find optimal quality level, purchase price, and selling quantity for the immediate firms, but his model is not valid in a production system where all units produced are not good. Mahapatra and Maiti [14] developed a multiobjective, multi-item inventory model with quality and stock-dependent demand rate. Their paper did not focus neither on the influence of selling price in demand nor on the defective product. Chen and Liu [15] proposed an optimal consignment policy considering a fixed fee and a per unit commission. Their model determines a higher manufacturer's profit than the traditional production system and coordinates the retailer to obtain a large supply chain profit. Chen [16] modified the model of Chen and Liu [15] by incorporating the influence of retailer's order quantity on the manufacturer's product quality. He considered the quality of the product as normally distributed. None of the above articles explained the joint determination of best selling price, product quality, and product quantity under qualitydependent production rate and costs.

In the present paper, the author has attempted to develop an inventory model to integrate the above mentioned factors. The salient features of this developed model are as follows:

(i) demand rate depends upon quality and selling price (selling markup rate);

(ii) a fraction of items produced are defective and only a fraction of defective items are repairable;

(iii) unit cost and carrying cost are variables, dependent upon quality;

(iv) production rate is quality dependent.

This model maximizes the average net profit per unit time and determines the best suitable quality and the best possible markup for selling price. It also determines the optimum production quantity in each cycle. This model is suitable for a manufacturing system where the manufacturer wants to jointly determine the quality (grade) of the item that should be produced and the selling price of the items to maximize the average net profit per unit time. The model is illustrated by numerical examples. A sensitivity analysis has been performed.

\section{Assumptions and Notation}

The following assumptions and notations are used in the developed model.

Production Process. The production process is not completely perfect. A fraction of the items produced are defective. A fraction of the defective items can be repaired to make it perfect. The rest cannot be repaired and will be disposed.

Quality of the Product. The item can be produced in different qualities, but the manufacturer wants to market a particular quality which will be most profitable. Actually, types of raw materials used, skills of the workers working in the production line, and quality of machineries used in the production system are responsible for the quality. The quality is assumed to be under manufacturer's control. Quality is represented by a quality index $r, 0<r_{1} \leq r \leq 1$. Here, $r_{1}$ is the minimum quality that is required to market the product. $r=1$ indicates the top quality.

Production Rate. The production rate depends upon the quality. The production rate $P(r)$ is a decreasing function of $r$. It means the rate decreases when the quality improves. This rate is taken in the following form:

$$
P(r)=P_{1}+\frac{P_{2}}{r}, \quad 0<r_{1} \leq r \leq 1,
$$

where $P_{1}$ represents the constant part of the production rate which does not depend upon the quality and the second part $P_{2} / r$ decreases with quality. It can be noticed that $P_{\min }=P_{1}+$ $P_{2}$ and $P_{\max }=P_{1}+\left(P_{2} / r_{1}\right)$. This type of production rate can be seen in Datta [11].

Unit Cost. The unit cost $C_{u}(r)$ of the item depends on the quality. The cost increases with quality. The following linear form is taken for unit cost $C_{u}(r): C_{u}(r)=a+b r$ where $a$ and $b$ are two positive constants. It can be noticed that $a+b r_{1} \leq C_{u} \leq a+b$.

Carrying Cost. Carrying/holding cost is $C_{h}(r)$ per unit time. This cost increases with quality $r$ and is taken in the quadratic form: $C_{h}(r)=p+q r^{2}$ where $p$ and $q$ are positive constants.

Consider the following

$\alpha$ : fraction of items produced that are defective;

$\beta$ : fraction of defective items that can be repaired to make it perfect;

$C_{s}$ : setup cost per production run;

$C_{d}$ : disposal cost per unit for disposing nonrepairable items;

$C_{r}$ : cost of repairing one unit;

$k$ : markup rate for selling $(k>0)$. Selling price is $s=$ $k C_{u}(r)$ for each unit of the product of quality $r$. But to earn profit, $k$ should be greater than 1 . 


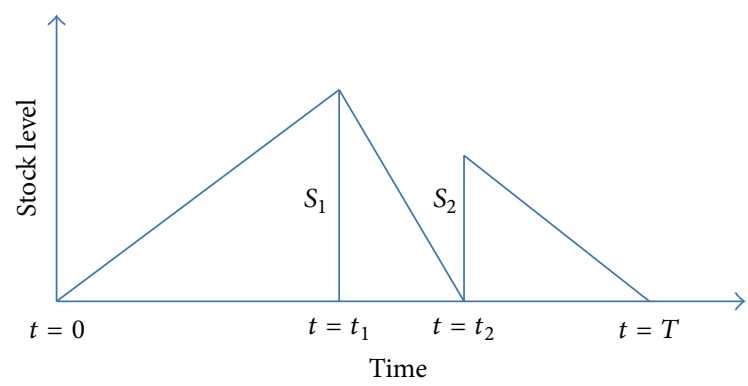

FIgURE 1: Pictorial representation of the system.

Time Horizon. Time horizon is infinite.

Shortages. Shortages are not allowed.

Demand Rate. Demand rate $D(k, r)$ depends upon both markup rate $k$ and the quality $r . D(k, r)$ decreases with $k$. Normally, $D(k, r)$ is an increasing function of $r$, but in some situations customers judge the quality by its price. If price is too low, they will doubt the quality and refuse to buy. This implies that for a given $k$, demand will increase with $r$ up to a certain level, and then it will decrease.

Further, $D(k, r)$ should be concave in $k$. Thus, the following conditions should be satisfied by $D(k, r): D_{k}<0, D_{k k}<0$, where suffix $\left({ }^{*}\right)$ indicates the partial derivative with respect to “*”.

Following condition must be satisfied by $D(k, r)$ :

$$
(1-\alpha) P(r)-D(k, r)>0 .
$$

\section{The Proposed System}

Production starts just after time $t=0$. Each unit will be inspected by an automated inspection system immediately after its production. Defective units will be immediately shifted to the repairing shop, repairing shop will separate the repairable and nonrepairable defective units. An amount $C_{d}$ (disposal cost) will be charged for disposing each unit. $C_{r}$ is the cost of repairing each unit to make it perfect. These repaired units will be brought to the selling area immediately when the stock level at the selling area is zero. A typical graph of the system is shown in Figure 1. Production and consumption will jointly continue during $\left[0, t_{1}\right]$. The level of inventory at time $t=t_{1}$ is $S_{1}$. Production stops at time $t=t_{1}$. There will be only consumption during $\left[t_{1}, t_{2}\right]$. Stock level becomes zero at time $t=t_{2}$. Immediately, repaired units will be brought which will raise the inventory level to $S_{2}$ at time $t=t_{2}$.

This initial stock level $S_{2}$ will gradually decrease due to market demand and becomes zero at time $t=T$. The time period $[0, T]$ defines a complete replenishment cycle.

\section{Revenue Calculation}

The following costs are involved in the proposed inventory system: setup cost, unit cost, carrying cost, repairing cost, and disposal cost. The policy adopted here is to maximize the average net revenue (ANR) per unit time over a replenishment cycle. The decision variables are production period $\left(t_{1}\right)$, markup rate $(k)$, and the quality level $(r)$.

Revenue calculation details

Total amount produced during $\left[0, t_{1}\right]=P(r) t_{1}$.

Total amount of defective items produced $=\alpha P(r) t_{1}$.

Total amount of repairable defective items = $\alpha \beta P(r) t_{1}$.

Total amount of nonrepairable defective items that will be disposed $=\alpha(1-\beta) P(r) t_{1}$.

Total amount of perfect items produced $=(1-$ $\alpha) P(r) t_{1}$.

The inventory level $S_{1}$ at time $t=t_{1}$ can be expressed as $S_{1}=[(1-\alpha) P(r)-D(k, r)] t_{1}$.

Fresh level of inventory at time $t=t_{2}$ is $S_{2}=\alpha \beta P(r) t_{1}$.

The following expressions of $t_{2}$ and $T$ are obtained: $t_{2}=t_{1}+\left(S_{1} / D(k, r)\right)=(1-\alpha) P(r) t_{1} / D(k, r)$, and

$T=t_{2}+\left(S_{2} / D(k, r)\right)=(1-\alpha+\alpha \beta) P(r) t_{1} / D(k, r)$.

Total production cost in a cycle $=C_{u}(r) P(r) t_{1}$.

Setup cost $=C_{s}$.

Total disposal cost $=C_{d} \alpha(1-\beta) P(r) t_{1}$.

Total repairing cost $=C_{r} \alpha \beta t_{1} P(r)\left(C_{r}<C_{u}\right)$.

Total carrying cost $=\left(C_{h}(r) / 2\right)\left[S_{1} t_{2}+S_{2}\left(T-t_{2}\right)\right]=$ $\left(C_{h}(r) / 2 D(k, r)\right)\left[\left\{\alpha^{2} \beta^{2}+(1-\alpha)^{2}\right\}\{P(r)\}^{2}-D(k, r)(1-\right.$

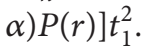

Gross revenue $=k C_{u}(r)(1-\alpha+\alpha \beta) P(r) t_{1}$.

Hence, the average net revenue (ANR) per unit time is

$$
\begin{aligned}
& \operatorname{ANR}\left(t_{1}, k, r\right) \\
& =\frac{1}{T} \times\left[\begin{array}{l}
\text { gross revenue }- \text { setup cost } \\
\text {-production cost - repairing cost } \\
\text {-disposal cost }- \text { holding cost }
\end{array}\right] \\
& =k C_{u}(r) D(k, r)-\frac{D(k, r)}{1-\alpha+\alpha \beta} \\
& \quad \times\left[\frac{C_{s}}{P(r) t_{1}}+C_{u}(r)+C_{d} \alpha(1-\beta)+C_{r} \alpha \beta\right] \\
& \quad-\frac{C_{h}(r) t_{1}}{2(1-\alpha+\alpha \beta)} \\
& \quad \times\left[\left\{\alpha^{2} \beta^{2}+(1-\alpha)^{2}\right\} P(r)-(1-\alpha) D(k, r)\right] .
\end{aligned}
$$




\section{Solution of the Model}

The necessary conditions for the existence of a maximum value of ANR for a given value of $r$ are

$$
\begin{aligned}
& \frac{\partial \mathrm{ANR}}{\partial t_{1}}=0, \quad \frac{\partial \mathrm{ANR}}{\partial k}=0 . \\
& \text { Now, } \frac{\partial \mathrm{ANR}}{\partial t_{1}}=0 \Longrightarrow
\end{aligned}
$$

$$
=\sqrt{\frac{t_{1}}{C_{h}(r) P(r)\left[\left\{\alpha^{2} \beta^{2}+(1-\alpha)^{2}\right\} P(r)-(1-\alpha) D(k, r)\right]}} .
$$

Also,

$$
\frac{\partial^{2} \mathrm{ANR}}{\partial t_{1}{ }^{2}}=-\frac{2 C_{s} D(k, r)}{(1-\alpha+\alpha \beta) P(r) t_{1}{ }^{3}}<0 .
$$

This implies that for given values of $k$ and $r$, ANR is maximum at $t_{1}$ defined by (5).

Property 1. The expression under the square root is positive.

Proof. The expression under the square root will be positive if $\left\{\alpha^{2} \beta^{2}+(1-\alpha)^{2}\right\} P(r)-(1-\alpha) D(k, r)$ is positive.

Now,

$$
\begin{aligned}
& \left\{\alpha^{2} \beta^{2}+(1-\alpha)^{2}\right\} P(r)-(1-\alpha) D(k, r) \\
& \quad=\alpha^{2} \beta^{2} P(r)+(1-\alpha)[(1-\alpha) P(r)-D(k, r)] .
\end{aligned}
$$

But, by $(2),(1-\alpha) P(r)-D(k, r)>0$.

Hence, the expression under the square root is positive. (proved)

$$
\begin{aligned}
& \text { Moreover, } \\
& \frac{\partial \mathrm{ANR}}{\partial k}=0 \Longrightarrow \\
& C_{u}(r) D(k, r)+\left[K C_{u}(r)-X\left(t_{1}\right)+Y\left(t_{1}\right)\right] D_{k}=0,
\end{aligned}
$$

where

$$
\begin{aligned}
X\left(t_{1}\right)= & \frac{1}{1-\alpha+\alpha \beta} \\
& \times\left[\frac{C_{s}}{P(r) t_{1}}+C_{u}(r)+\alpha(1-\beta) C_{d}+\alpha \beta C_{r}\right], \\
Y\left(t_{1}\right)= & \frac{C_{h}(1-\alpha) t_{1}}{2(1-\alpha+\alpha \beta)}, \quad X\left(t_{1}\right), Y\left(t_{1}\right)>0 .
\end{aligned}
$$

The sufficient conditions for maximum are

$$
\begin{aligned}
& \text { (a) } \frac{\partial^{2} \mathrm{ANR}}{\partial t_{1}{ }^{2}}<0, \\
& \text { (b) } \frac{\partial^{2} \mathrm{ANR}}{\partial k^{2}}<0, \\
& \text { (c) } \frac{\partial^{2} \mathrm{ANR}}{\partial t_{1}{ }^{2}} \cdot \frac{\partial^{2} \mathrm{ANR}}{\partial k^{2}}-\left\{\frac{\partial^{2} \mathrm{ANR}}{\partial t_{1} \partial k}\right\}^{2}>0 .
\end{aligned}
$$

The first condition (a) has already been proved. If we look at (3), we will see that $D(k, r) \cdot X\left(t_{1}\right)$ is the sum of ordering cost, unit cost, disposal cost, and repairing cost per unit time, whereas $k C_{u} D(k, r)$ is the selling price per unit. For any business, $k C_{u} \cdot D(k, r)>X\left(t_{1}\right) D(k, r)$ or $k C_{u}>X\left(t_{1}\right)$. This leads to the result $k C_{u}-X\left(t_{1}\right)+Y\left(t_{1}\right)>0$.

Hence, $\partial^{2} \mathrm{ANR} / \partial k^{2}=2 C_{u} D_{k}(k, r)+\left[k C_{u}-X\left(t_{1}\right)+\right.$ $\left.Y\left(t_{1}\right)\right] D_{k k}<0$. This proved (b).

It is very difficult to give an analytical proof of (c). However for given values of the model parameters this can be proved. For a given value of $r$, the most economic values $t_{1}^{*}$ and $k^{*}$ of $t_{1}$ and $k$ can be obtained by jointly solving (5) and (8). These values of $t_{1}$ and $k$ will give the maximum value of ANR for a given quality $r$. The optimum production quantity $Q^{*}$ in each cycle will satisfy the following equation:

$$
\begin{aligned}
Q^{*} & =P(r) t_{1} \\
& =\sqrt{\frac{2 C_{s} D(k, r)}{C_{h}(r)\left[\alpha^{2} \beta^{2}+(1-\alpha)^{2}-(1-\alpha)(D(k, r) / P(r))\right]}} .
\end{aligned}
$$

An algorithm is given below for solving the problem.

Algorithm.

Step 1. Select a demand pattern. Enter the values of the model parameters.

Step 2. Select the increment of $r$, say $i$. The value of " $i$ " can be taken as 0.1 or 0.01 . Use a counter $j$. Take $j=1$.

Step 3. Take $r=r_{1}, k=1$.

Step 4. Find $t_{1}$ by using (5).

Step 5. Find $k$ by (8).

Step 6. Repeat Steps 3, 4, and 5 until the values of $k$ and $t_{1}$ become stable.

Step 7. Calculate ANR using (3). Let this value be $\operatorname{ANR}(j)$.

Step 8. $r=r_{1}+i$.

Step 9. If $r>1$, move to the next step. Else $j=j+1$ and go to Step 3. 
TABLE 1: Values of the model parameters.

\begin{tabular}{|c|c|c|c|c|c|c|c|c|c|c|c|c|c|c|}
\hline Parameter & $m$ & $n$ & $a$ & $b$ & $P_{1}$ & $P_{2}$ & $r_{1}$ & $p$ & $q$ & $\alpha$ & $\beta$ & $C_{d}$ & $C_{r}$ & $C_{s}$ \\
\hline Value & 120 & 25 & 12 & 20 & 300 & 100 & 0.2 & 6 & 8 & 0.4 & 0.5 & 5 & 15 & 200 \\
\hline
\end{tabular}

TABLE 2: Optimum results and hessian value.

\begin{tabular}{lccccccc}
\hline$r^{*}$ & $k^{*}$ & $t_{1}^{*}$ & $\mathrm{ANR}^{*}$ & $\mathrm{ANR}_{t_{1} t_{1}}$ & $\mathrm{ANR}_{k k}$ & $\mathrm{ANR}_{t_{1} k}$ & $H$ \\
0.54 & 2.33788 & 0.31657 & 289.55 & -2042.03 & -908.223 & -548.01 & 1554309.79 \\
\hline
\end{tabular}

Suffix "*" in ANR indicates partial derivative with respect to "*”. " $H$ " stands for the hessian at the optimal values of the decision variables.

TABLE 3: Values of the model parameters.

\begin{tabular}{lccccccccccccccc}
\hline Parameter & $u$ & $v$ & $w$ & $a$ & $b$ & $P_{1}$ & $P_{2}$ & $r_{1}$ & $p$ & $q$ & $\alpha$ & $\beta$ & $C_{d}$ & $C_{r}$ & $C_{s}$ \\
Value & 200 & 30 & 80 & 12 & 20 & 300 & 50 & 0.2 & 6 & 8 & 0.2 & 0.5 & 5 & 15 & 1000 \\
\hline
\end{tabular}

Step 10. Compare the values of $\operatorname{ANR}(j)$ and find $j$ for which it is maximum. The corresponding values of $r, k, t_{1}$ will give us the solution of the model.

Step 11. Stop.

\section{Some Special Cases}

Case 4. If we substitute $\beta=0$ in (5), it will give us the optimum production period in each cycle as

$$
t_{1}=\sqrt{\frac{2 C_{s} D(k, r)}{C_{h}(r) P(r)\left[\left\{(1-\alpha)^{2}\right\} P(r)-(1-\alpha) D(k, r)\right]}},
$$

Case 1. When $\alpha=0$,

$$
Q^{*}=\sqrt{\frac{2 C_{s} D(k, r)}{C_{h}(r)[1-(D(k, r) / P(r))]}} .
$$

This is optimal production quantity (OPQ) when all items produced are perfect. It can be noted that this expression of OPQ is similar to the basic inventory model with finite production rate and without shortages. Further, if we take limit as $P(r) \rightarrow \infty$, then $Q^{*}=\sqrt{2 C_{s} D(k, r) / C_{h}(r)}$ which is classical EOQ formula.

Case 2. When $\beta=0$,

$$
Q^{*}=\sqrt{\frac{2 C_{s} D(k, r)}{C_{h}(r)(1-\alpha)[(1-\alpha)-(D(k, r) / P(r))]}} .
$$

This is OPQ when all defective items are nonrepairable. If we further take limit as $P(r) \rightarrow \infty$, then $Q^{*}=$ $\sqrt{2 C_{s} D(k, r) / C_{h}(r)(1-\alpha)^{2}}$ which is similar to (10) of Salameh and Jaber [7] when defective rate $p$ is constant and screening rate $x \rightarrow \infty$.

Case 3. When $\beta=1$,

$$
Q^{*}=\sqrt{\frac{2 C_{s} D(k, r)}{C_{h}(r)\left[\alpha^{2}+(1-\alpha)^{2}-(1-\alpha)(D(k, r) / P(r))\right]}} .
$$

This is OPQ when all defective items are repairable. which is similar to (2) of Datta [11] except the last term in the denominator. Datta's [11] article assumed that the defective items would be separated at the end of the production period. Due to this reason, the last term is different.

\section{Numerical Examples}

Example 1. Demand pattern $D(k, r)=m r-n r^{2} k^{2}$.

The demand rate is taken in a nonlinear form: $D(k, r)=$ $m r-n r^{2} k^{2}$, where $m$ and $n$ are positive constants $(m>n)$. It can be observed that $D_{k}<0, D_{k k}<0$. For a positive demand, $\left(0, k_{1}\right)$. Parameter values are given in Table 1.

Solution. Results are shown in Table 2.

Example 2. Linear demand pattern $D(k, r)=u+v r-w k$.

Let us analyze the model for a linear demand pattern in the form: $D(k, r)=u+v r-w k$ where $u, v, w>0$. It can be observed that $D$ satisfies the condition $D_{k}<0$. One advantage of this linear form is that one can easily estimate the constants $u, v, w$ by using multiple linear regression. The demand must be positive, that is, $D>0$. This condition gives $k<(u+v r) / w=k_{1}$, say. Thus, the value of $k$ lies in the open interval $\left(0, k_{1}\right)$. Parameter values are given in Table 3 .

Solution. Results are shown in Table 4. $k<\sqrt{m / n r}=k_{1}$. Thus, the value of $k$ lies in the interval 
TABLE 4: Optimum results and hessian value.

\begin{tabular}{cccccccc}
\hline$r^{*}$ & $k^{*}$ & $t_{1}^{*}$ & $\mathrm{ANR}^{*}$ & $\mathrm{ANR}_{t_{1} t_{1}}$ & $\mathrm{ANR}_{k k}$ & $\mathrm{ANR}_{t_{1} k}$ \\
1 & 2.1263 & 0.3689 & 781.98 & -7571.7 & -5120 & -1919.52 & $3.5 e+07$ \\
\hline
\end{tabular}

Suffix “*” in ANR indicates partial derivative with respect to "*”. " $H$ " stands for the hessian at the optimal values of the decision variables.

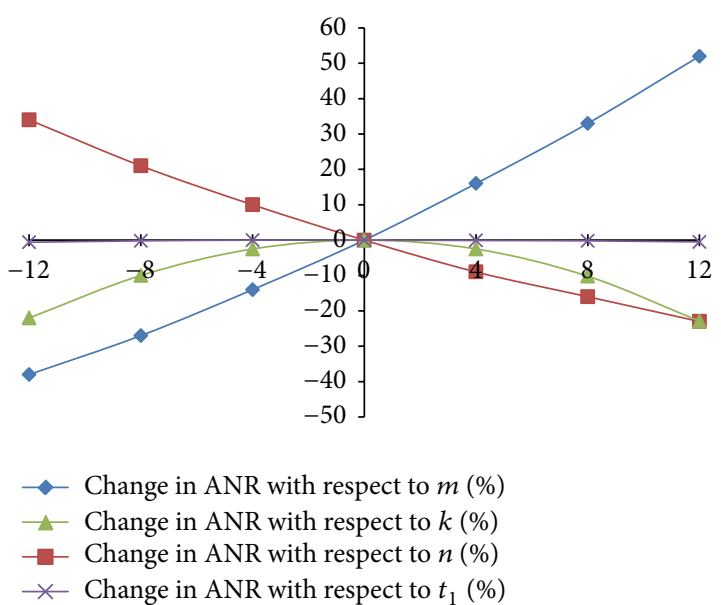

FIgURE 2: \% change in ANR (Example 1).

\section{Sensitivity Analysis}

In this section, a sensitivity analysis has been performed to analyze the effects of demand parameters and decision variables $k, t_{1}$ on the average net profit ANR. The previous numerical problems are considered for this sensitivity analysis. The changes of ANR for the changes of these parameters/variables are shown in Table 5.

8.1. Analysis of Nonlinear Demand Pattern (Example 1). It can be observed that demand parameters $m$ and $n$ are very sensitive parameters. ANR increases rapidly with the increase of the value of $m$. But rate of increase is more for higher values of $m$. The parameter $n$ is relatively less sensitive. The parameter $n$ is relatively more sensitive for lower values than higher values. The decision parameter $k$ is more sensitive than the other decision parameter $t_{1}$. A change in the value of $k$ by $12 \%$ causes more than $20 \%$ decrease in the value of ANR.

8.2. Analysis of Linear Demand Pattern (Example 2). The demand parameters $u$ and $w$ are very sensitive. The parameter $u$ is more sensitive for higher values, but $w$ is more sensitive for lower values. The demand parameter $v$ is relatively less sensitive. The decision variable $t_{1}$ is very less sensitive. The sensitivity of $k$ is moderate. To get a better idea about the sensitiveness previous results are graphically presented in Figures 2 and 3 . The following are the managerial insights of the above analysis:

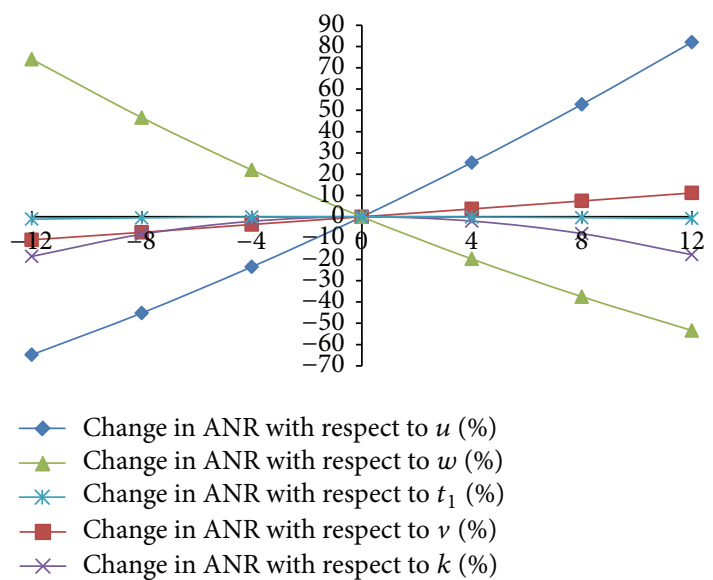

FIgURE 3: \% change in ANR (Example 2).

(i) proper care should be taken while estimating the demand parameters. A small error in these parameters may mislead the production manager;

(ii) if the production manager is forced to change the optimal production time by a small amount of time, it will not make a significant difference in the optimal profit.

\section{Concluding Remarks}

This paper described how to solve a managerial problem associated with a faulty production system which produces a combination of perfect and defective units. It is assumed that only a fraction of defective products are repairable. This model jointly determines the quality of the product and selling price which will maximize the average net revenue per unit time. A general model is developed. For illustrating the model, two numerical problems are presented with two demand patterns. Sensitivity analysis is performed for both examples. An algorithm is provided for solving the model. This algorithm helps in generating computer codes. However, standard optimizing software, like MATLAB, can be used for solving this model. In MATLAB, fmincon function can be used. The model considers quality as a continuous variable described by the quality index $r$, but a situation may arise where manufacturer/business organization may face the problem to select the appropriate quality out of a finite number of quality options. It means that the quality has a discrete set of options. The previous model can be used to tackle this situation with a minor modification. In 
TABLE 5: Results of sensitivity analysis.

\begin{tabular}{|c|c|c|c|}
\hline $\begin{array}{l}\text { Parameter/ } \\
\text { decision variable }\end{array}$ & $\%$ change & ANR & $\%$ change in ANR \\
\hline \multicolumn{4}{|c|}{ Example 1} \\
\hline \multirow{6}{*}{$m$} & $-12 \%$ & 178.64 & -38.3 \\
\hline & $-8 \%$ & 211.65 & -26.9 \\
\hline & $-4 \%$ & 248.52 & -14.2 \\
\hline & $+4 \%$ & 335.03 & 15.7 \\
\hline & $+8 \%$ & 385.31 & 33.1 \\
\hline & $+12 \%$ & 440.82 & 52.2 \\
\hline \multirow{6}{*}{$n$} & $-12 \%$ & 388.38 & 34.1 \\
\hline & $-8 \%$ & 350.62 & 21.1 \\
\hline & $-4 \%$ & 317.96 & 9.8 \\
\hline & $+4 \%$ & 264.67 & -8.6 \\
\hline & $+8 \%$ & 242.75 & -16.2 \\
\hline & $+12 \%$ & 223.42 & -22.8 \\
\hline \multirow{6}{*}{$k$} & $-12 \%$ & 227.02 & -21.6 \\
\hline & $-8 \%$ & 261.37 & -9.7 \\
\hline & $-4 \%$ & 282.42 & -2.5 \\
\hline & $+4 \%$ & 282.26 & -2.5 \\
\hline & $+8 \%$ & 260.14 & -10.2 \\
\hline & $+12 \%$ & 223.10 & -22.9 \\
\hline \multirow{6}{*}{$t_{1}$} & $-12 \%$ & 287.88 & -0.6 \\
\hline & $-8 \%$ & 288.84 & -0.2 \\
\hline & $-4 \%$ & 289.38 & -0.0 \\
\hline & $+4 \%$ & 289.39 & -0.1 \\
\hline & $+8 \%$ & 288.94 & -0.2 \\
\hline & $+12 \%$ & 288.23 & -0.5 \\
\hline \multicolumn{4}{|c|}{ Example 2} \\
\hline \multirow{6}{*}{$u$} & $-12 \%$ & 275.51 & -64.8 \\
\hline & $-8 \%$ & 428.91 & -45.2 \\
\hline & $-4 \%$ & 597.84 & -23.5 \\
\hline & $+4 \%$ & 981.07 & 25.5 \\
\hline & $+8 \%$ & 1194.93 & 52.8 \\
\hline & $+12 \%$ & 1423.41 & 82.0 \\
\hline \multirow{6}{*}{$v$} & $-12 \%$ & 697.25 & -10.8 \\
\hline & $-8 \%$ & 725.16 & -7.3 \\
\hline & $-4 \%$ & 753.40 & -3.6 \\
\hline & $+4 \%$ & 810.89 & 3.7 \\
\hline & $+8 \%$ & 840.14 & 7.44 \\
\hline & $+12 \%$ & 869.73 & 11.2 \\
\hline \multirow{6}{*}{$w$} & $-12 \%$ & 1360.31 & 74.0 \\
\hline & $-8 \%$ & 1146.04 & 46.6 \\
\hline & $-4 \%$ & 954.12 & 22.0 \\
\hline & $+4 \%$ & 627.44 & -19.8 \\
\hline & $+8 \%$ & 488.69 & -37.5 \\
\hline & $+12 \%$ & 364.16 & -53.4 \\
\hline
\end{tabular}

TABLE 5: Continued.

\begin{tabular}{lccc}
\hline $\begin{array}{l}\text { Parameter/ } \\
\text { decision variable }\end{array}$ & \% change & ANR & \% change in ANR \\
\hline \multirow{4}{*}{$k$} & $-12 \%$ & 636.63 & -18.6 \\
& $-8 \%$ & 717.61 & -8.2 \\
& $-4 \%$ & 765.91 & -2.1 \\
& $+4 \%$ & 766.40 & -2.0 \\
& $+8 \%$ & 719.95 & -7.9 \\
& $+12 \%$ & 642.66 & -17.8 \\
\hline & $-12 \%$ & 773.68 & -1.1 \\
& $-8 \%$ & 778.28 & -0.5 \\
$t_{1}$ & $-4 \%$ & 781.10 & -0.1 \\
& $+4 \%$ & 781.15 & -0.1 \\
& $+8 \%$ & 779.01 & -0.4 \\
& $+12 \%$ & 775.41 & -0.8 \\
\hline
\end{tabular}

this situation, find the best ANR for each of these possible qualities and then compare the values to find the most appropriate quality.

There is enough scope to extend this model by incorporating shortages, inflation, and stock-dependent demand rate.

\section{Conflict of Interests}

The author declares no conflict of interests with the software package MATLAB.

\section{Acknowledgments}

The author deeply appreciates anonymous referees for their valuable comments/suggestions.

\section{References}

[1] E. S. Maynes, Household Production and Consumption, National Bureau of Economic Research, Cambridge, Mass, USA, 1976.

[2] R. Jiang, "A product quality index derived from product lifetime distribution," in Proceedings of the International Conference on Measuring Technology and Mechatronics Automation (ICMTMA '09), pp. 573-577, April 2009.

[3] A. Huidobro, A. Pastor, and M. Tejada, "Quality index method developed for raw gilthead seabream (Sparus aurata)," Journal of Food Science, vol. 65, no. 7, pp. 1202-1205, 2000.

[4] A. Barbosa and P. Vaz-Pires, "Quality index method (QIM): development of a sensorial scheme for common octopus (Octopus vulgaris)," Food Control, vol. 15, no. 3, pp. 161-168, 2004.

[5] M. J. Rosenblatt and H. L. Lee, "Economic production cycles with imperfect production processes," IIE Transactions, vol. 18, no. 1, pp. $48-55,1986$.

[6] C. H. Kim and Y. Hong, "An optimal production run length in deteriorating production processes," International Journal of Production Economics, vol. 58, no. 2, pp. 183-189, 1999.

[7] M. K. Salameh and M. Y. Jaber, "Economic production quantity model for items with imperfect quality," International Journal of Production Economics, vol. 64, no. 1, pp. 59-64, 2000. 
[8] K. Chung and K. Hou, "An optimal production run time with imperfect production processes and allowable shortages," Computers and Operations Research, vol. 30, no. 4, pp. 483-490, 2003.

[9] Y. P. Chiu, "Determining the optimal lot size for the finite production model with random defective rate, the rework process, and backlogging," Engineering Optimization, vol. 35, no. 4, pp. 427-437, 2003.

[10] S. S. Sana, "A production-inventory model in an imperfect production process," European Journal of Operational Research, vol. 200, no. 2, pp. 451-464, 2010.

[11] T. K. Datta, "Production rate and selling price determination in an inventory system with partially defective products," IST Transactions of Applied Mathematics-Modeling and Simulation, vol. 1, no. 2, pp. 15-19, 2010.

[12] F. Mhada, A. Hajji, R. Malhamé, A. Gharbi, and R. Pellerin, "Production control of unreliable manufacturing systems producing defective items," Journal of Quality in Maintenance Engineering, vol. 17, no. 3, pp. 238-253, 2011.

[13] C. Chen, "Optimal determination of quality level, selling quantity and purchasing price for intermediate firms," Production Planning \& Control, vol. 11, no. 7, pp. 706-712, 2000.

[14] N. K. Mahapatra and M. Maiti, "Multi-objective inventory models of multi-items with quality and stock-dependent demand and stochastic deterioration," Advanced Modeling and Optimization, vol. 7, no. 1, pp. 69-84, 2005.

[15] S. L. Chen and C. L. Liu, "The optimal consignment policy for the manufacturer under supply chain co-ordination," International Journal of Production Research, vol. 46, no. 18, pp. 51215143, 2008.

[16] C. Chen, "The joint determination of optimum process mean and economic order quantity," Tamkang Journal of Science and Engineering, vol. 14, no. 4, pp. 303-312, 2011. 


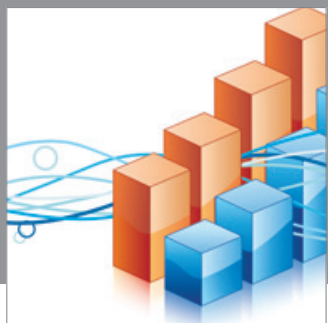

Advances in

Operations Research

mansans

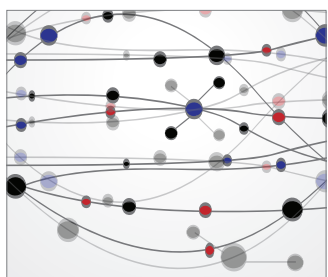

The Scientific World Journal
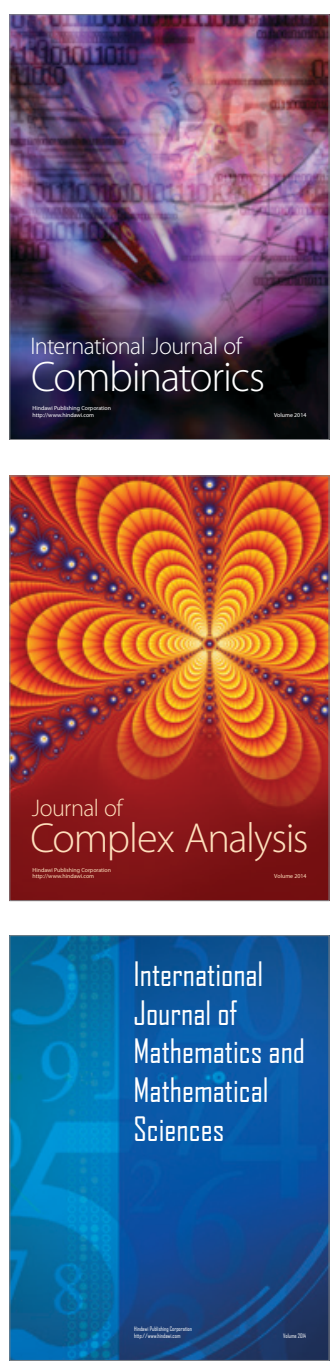
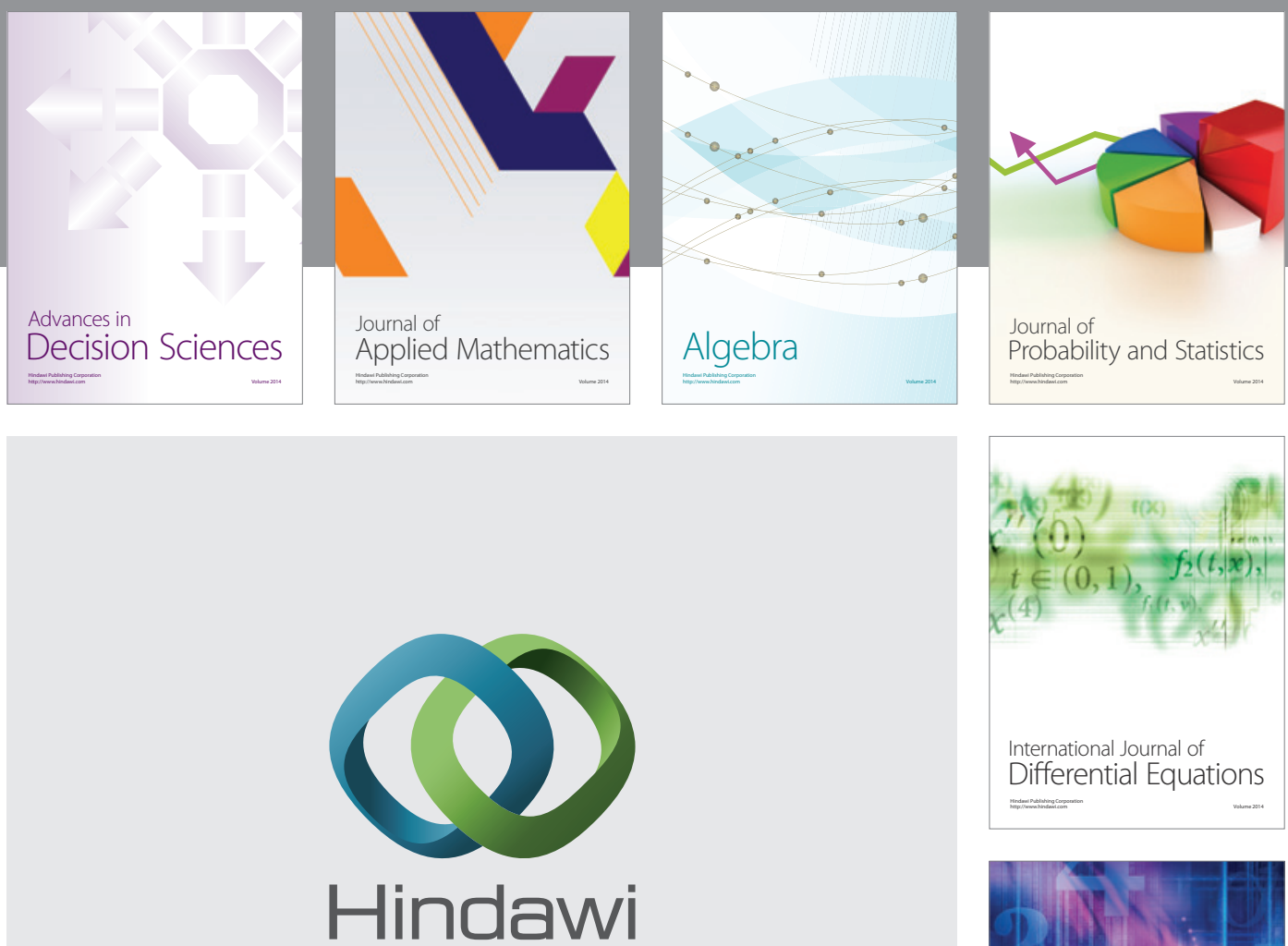

Submit your manuscripts at http://www.hindawi.com
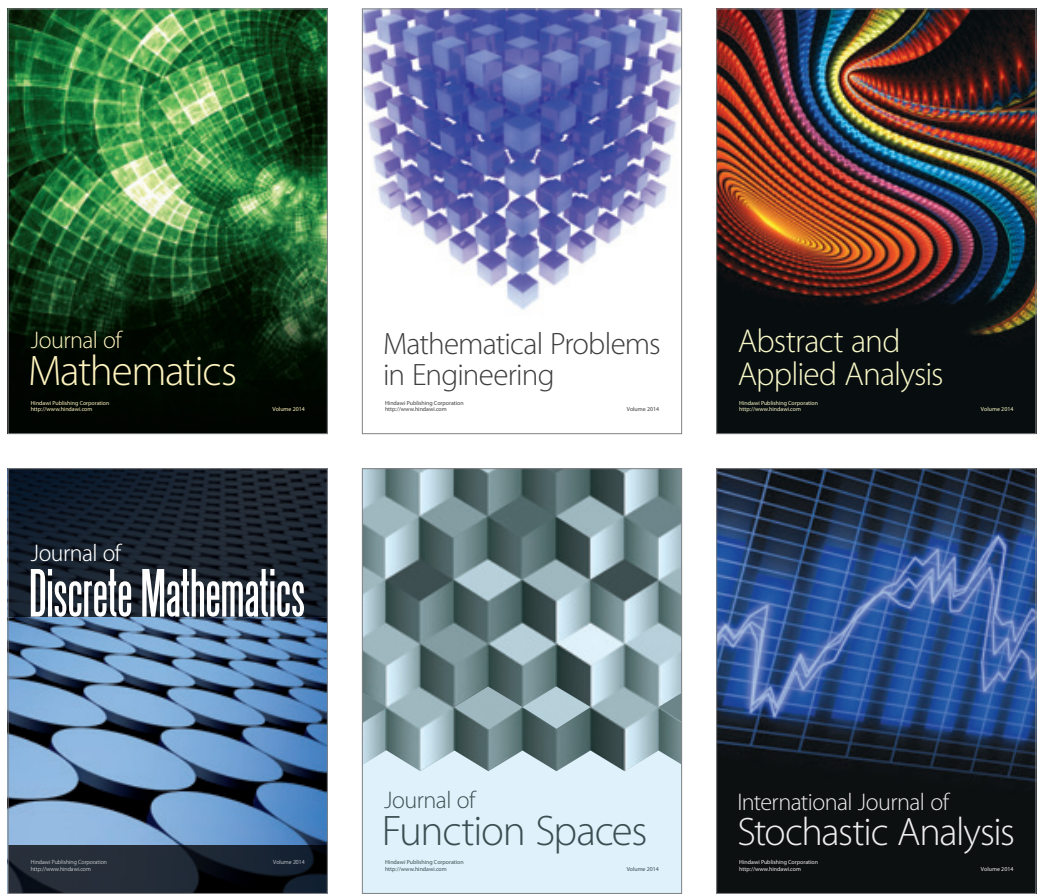

Journal of

Function Spaces

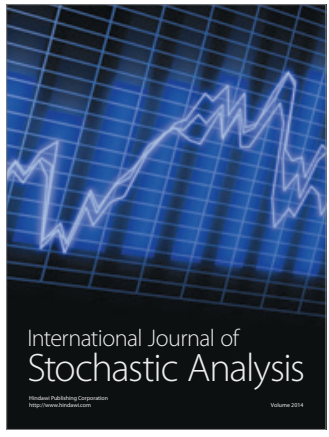

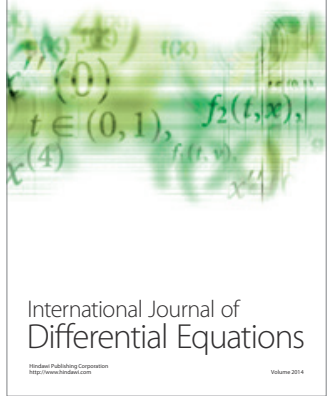
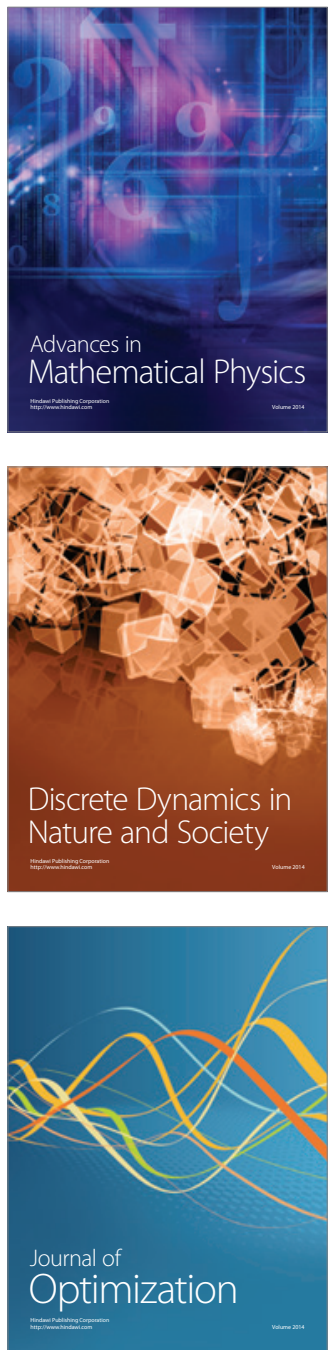